\title{
Effects of anaerobic and microaerophilic conditions of extraction and incubation on the survival of Treponema pallidum in vitro
}

\author{
G H W WONG, B M STEINER, AND S R GRAVES \\ From the Department of Microbiology, Monash University Medical School, Alfred Hospital, Prahran, \\ Victoria, Australia
}

SUMMARY Treponema pallidum extracted from infected rabbit testes under anaerobic conditions survived longer in vitro than those extracted under aerobic conditions. Anaerobically extracted treponemes were incubated anaerobically for $0,12,24,36$, or 48 hours and then exposed to microaerophilic conditions ( $3 \%$ oxygen) for further incubation. Treponemes transferred to microaerophilic conditions after 36 or 48 hours' anaerobic incubation maintained significantly greater viability compared with those kept under constant microaerophilic conditions, although there was no difference after 12 or 24 hours. $T$ pallidum incubated under constant anaerobic conditions, however, usually maintained greater viability than those kept under constant microaerophilic conditions.

These results suggest that $T$ pallidum is sensitive to oxygen toxicity both during initial extraction from orchitic rabbit testes and subsequent incubation in vitro. In the latter case, it can be partially protected by a period of anaerobic incubation in vitro, before exposure to microaerophilic conditions.

\section{Introduction}

Treponema pallidum has little ability to handle oxygen toxicity in vitro. Although high concentrations of oxygen enhanced the metabolism of $T$ pallidum in vitro, ${ }^{34}$ prolonged survival and growth have been observed only under low oxygen concentrations $^{56}$ and electronegative redox potentials. ${ }^{1}$

The survival of $T$ pallidum in vitro has been prolonged by several methods-presumably by reducing the toxicity of oxygen - such as the addition of reducing agents, ${ }^{7-9}$ co-incubation with tissue culture cells, ${ }^{9}$ and the addition of oxygen-protective enzymes (unpublished data).

In this paper we compared the survival of $T$ pallidum in vitro after either anaerobic or aerobic extraction from infected rabbit testes on the assumption that oxygen toxicity was minimal in the former case. We also tested the effect of a variable period of incubation under anaerobic conditions before the

Address for reprints: $\mathrm{Dr}$ G $\mathrm{H}$ W Wong, Department of Microbiology, Monash University Medical School, Alfred Hospital, Prahran, Victoria, Australia 3181

Accepted for publication 18 November 1981 treponemes were exposed to $3 \%$ oxygen to determine whether they were more sensitive to oxygen toxicity immediately after extraction from infected rabbit testes or at sometime later.

\section{Materials and methods}

The Nichols strain of $T$ pallidum was maintained by intratesticular passage in rabbits. $T$ pallidum was harvested within two days of orchitis appearing in the rabbit, which was killed by an intravenous injection of $3 \mathrm{ml}$ sodium pentobarbitone $(200 \mathrm{mg} / \mathrm{ml})$. The testes were removed aseptically and cut into longitudinal and transverse slices with sterile scissors.

\section{AEROBIC EXTRACTION}

After initial slicing, the testes were further cut and minced in a sterile Petri dish under aerobic conditions in a laminar flow cabinet. The first extract, containing large amounts of tissue debris and erythrocytes, was discarded. The minced testes were then eluted with reduced medium $(30 \mathrm{ml})$ and the extraction completed within 30-60 minutes. When the yield of treponemes was very low or the testicular tissue haemorrhagic or both, the treponemes were not 
used, since they were often found to be of low viability.

\section{ANAEROBIC EXTRACTION}

The slices of testicular tissue were placed in a bottle containing reduced medium $(30-50 \mathrm{ml})$ and then flushed with sterile oxygen-free nitrogen. The treponemes were eluted by gentle agitation for 30-60 minutes. The extract was then separated from the testicular tissue and counts made in a bacterial counting chamber by darkfield microscopy. The treponemes obtained by the two extraction methods were adjusted to the same concentration before inoculation into media.

A previously published medium, ${ }^{1}$ with $2 \mathrm{mmol} / 1$ dithiothreitol instead of sodium thioglycollate was used. The final $\mathrm{pH}$ was $7 \cdot 3 \pm 0 \cdot 1$, the redox potential $-350 \pm 50 \mathrm{mV}$ (Ecal), and the incubation temperature $34^{\circ} \mathrm{C}$. Anaerobic and microaerophilic incubation have been described. ${ }^{1}$

Percentage motility based on counts of $50-100$ treponemes by darkfield microscopy and virulence in rabbits, as shown by the latent period before lesions appeared after intradermal inoculation, ${ }^{1}$ were used for determining the viability of $T$ pallidum in vitro. Student's $t$ test was used to compare the differences between the data.

\section{Results}

COMPARISON OF EXTRACTION METHODS ON RETENTION OF VIABILITY AFTER MICROAEROPHILIC INCUBATION

No difference was detected between anaerobically and aerobically extracted treponemes after 24 and 48 hours' incubation. Both the percentage motilities of the cultures and their latent periods for lesion development in rabbits were similar (data not shown). However, significant differences were observed after 72 and 96 hours' incubation in vitro (table I). The anaerobically extracted treponemes maintained significantly higher percentage motility and virulence (shorter latent periods) than aerobically extracted treponemes.
SURVIVAL OF ANAEROBICALLY EXTRACTED TREPONEMES AFTER MICROAEROPHILIC INCUBATION

After anaerobic extraction treponemes were main tained under anaerobiosis for different periods $(0, \stackrel{\vec{\sim}}{\rightarrow}$ $12,24,36$, and 48 hours) before incubation in $3 \%$ 음 oxygen in nitrogen. The controls were treponemes incubated either anaerobically or under $3 \%$ oxygen. $\frac{\bar{S}}{\partial}$ After 12 or 24 hours' anaerobic incubation, followed by microaerophilic incubation, there was no significant difference in treponemal survival compared with

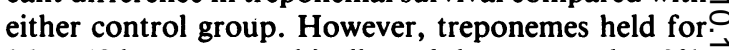
36 or 48 hours anaerobically and then exposed to $3 \% \overrightarrow{\vec{\omega}}$ oxygen survived significantly longer, as measured by percentage motility (table II), than those exposed to $\stackrel{0}{=}$ constant $3 \%$ oxygen when sampled at $60,72,96$, and 120 hours after harvesting. The latent periods of $\omega$ lesion formation in rabbits from treponemes $\vec{\omega}$ incubated anaerobically for $\mathbf{3 6}$ or $\mathbf{4 8}$ hours were also significantly shorter than those from treponemes incubated under constant $3 \%$ oxygen (table III). Treponemal survival was not significantly enhanced compared with those in the constant anaerobic $\overparen{\odot}$ control group. Treponemes usually maintained $\overrightarrow{0}$ viability longer under constant anaerobic conditions

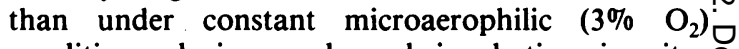
conditions during prolonged incubation in vitro (tables II and III).

\section{Discussion}

The anaerobically extracted treponemes survived $\overrightarrow{\overrightarrow{0}}$ longer in vitro than those extracted aerobically, suggesting that $T$ pallidum is sensitive to oxygen during the extraction process. Oxygen-derived species (superoxide free radical, hydroxyl free $\stackrel{s}{\rightleftharpoons}$. radical, singlet oxygen, and hydrogen peroxide) mayo act directly or indirectly on: (a) the DNA synthetic complex, ${ }^{10}$ the treponemes possibly having lost theo ability to initiate or continue DNA synthesis in vitro; (b) the extracellular layer, ${ }^{11}$ resulting in loss of virulence in vitro; or (c) the membranes and $D$ enzymes, ${ }^{12}$ causing a loss of biochemical function in vitro.

TABLE I Comparison of the effect of anaerobic and aerobic extraction of $T$ pallidum from infected tissue on the survival of motile and virulent treponemes after incubation in vitro

\begin{tabular}{|c|c|c|c|c|c|c|c|}
\hline \multirow[b]{2}{*}{ Incubation period (hours) } & \multicolumn{3}{|c|}{$\%$ Motility* $( \pm S D)$ after extraction: } & \multicolumn{4}{|c|}{ Latent period + (days $\pm S D)$ after extraction: } \\
\hline & Anaerobic & Aerobic & $P$ value & Experiment & Anaerobic & Aerobic & $P$ value \\
\hline 72 & $55 \cdot 2 \pm 7 \cdot 6$ & $28 \cdot 0 \pm 13 \cdot 6$ & $<0.01$ & $\begin{array}{l}1 \\
2\end{array}$ & $\begin{array}{r}8 \cdot 5 \pm 1 \cdot 1 \\
14 \cdot 5 \pm 0 \cdot 8\end{array}$ & $\begin{array}{l}12 \cdot 1 \pm 1 \cdot 0 \\
17 \cdot 3 \pm 1 \cdot 0\end{array}$ & $\begin{array}{l}<0.001 \\
<0.001\end{array}$ \\
\hline 96 & $24 \cdot 3 \pm 11 \cdot 9$ & $6 \cdot 0 \pm 2 \cdot 8$ & $<0 \cdot 05$ & $\begin{array}{l}1 \\
2\end{array}$ & $\begin{array}{l}15 \cdot 7 \pm 0.8 \\
16 \cdot 6 \pm 0.5\end{array}$ & $\begin{array}{l}20 \cdot 0 \pm 0 \\
18 \cdot 0 \pm 0 \cdot 8\end{array}$ & $\begin{array}{l}<0.001 \\
<0.02\end{array}$ \\
\hline
\end{tabular}

* Mean of counts of 200-600 treponemes in 4-6 samples (50-100 treponemes/sample) from two independent experiments.

tTime between rabbit inoculation and appearance of lesions (mean of 10 lesions for each experiment).

$\mathrm{P}=$ probability; $\mathrm{P}<0.05$ is significant (Student's $t$ test). 
TABLE II Effect of 36 or 48 hours' anaerobic incubation followed by incubation under $3 \%$ oxygen on the viability of $T$ pallidum as measured by the retention of motility

\begin{tabular}{|c|c|c|c|c|c|c|c|c|}
\hline \multirow[b]{3}{*}{ Incubation conditions } & \multicolumn{8}{|c|}{$\%$ Motilityt $( \pm S D)$ after different incubation periods in vitro $(h)$ : } \\
\hline & \multicolumn{3}{|c|}{ Experiment I } & \multicolumn{3}{|c|}{ Experiment 2} & \multicolumn{2}{|c|}{ Experiment 3} \\
\hline & 72 & 96 & 120 & 72 & 96 & 120 & 60 & 72 \\
\hline Constant $3 \% \mathrm{O}_{2}$ (control) & $56 \pm 4$ & $29 \pm 5$ & $20 \pm 1$ & $50 \pm 4$ & $35 \pm 2$ & $20 \pm 3$ & $11 \pm 1$ & $6 \pm 4$ \\
\hline Anaerobic $(36 \mathrm{~h})^{*}$ & $\begin{array}{c}74 \pm 1 \\
P<0.001\end{array}$ & $\begin{array}{c}57 \pm 4 \\
P<0.001\end{array}$ & $\begin{array}{c}52 \pm 1 \\
P<0.001\end{array}$ & $\begin{array}{c}79 \pm 1 \\
P<0.001\end{array}$ & $\begin{array}{c}66 \pm 4 \\
P<0 \cdot 001\end{array}$ & $\begin{array}{c}54 \pm 2 \\
P<0.001\end{array}$ & $\begin{array}{c}56 \pm 0 \\
P<0.001\end{array}$ & $\begin{array}{l}45 \pm 0.3 \\
P<0.005\end{array}$ \\
\hline Anaerobic (48 h)* & $\begin{array}{r}66 \pm 4 \\
P<0.01\end{array}$ & $\begin{array}{c}63 \pm 4 \\
P<0.001\end{array}$ & $\begin{array}{c}57 \pm 3 \\
P<0.001\end{array}$ & $\begin{array}{c}74 \pm 1 \\
P<0.001\end{array}$ & $\begin{array}{c}62 \pm 3 \\
\mathrm{P}<0.001\end{array}$ & $\begin{array}{c}47 \pm 4 \\
P<0 \cdot 001\end{array}$ & $\begin{array}{c}45 \pm 2 \\
P<0.005\end{array}$ & $\begin{array}{r}36 \pm 6 \\
P<0.05\end{array}$ \\
\hline Constant anaerobic (control) & $\begin{array}{r}64 \pm 4 \\
P<0.05\end{array}$ & $\begin{array}{l}34 \pm 5 \\
\text { NS }\end{array}$ & $\begin{array}{c}28 \pm 3 \\
P<0.005\end{array}$ & $\begin{array}{c}70 \pm 1 \\
P<0.001\end{array}$ & $\begin{array}{c}63 \pm 3 \\
P<0.001\end{array}$ & $\begin{array}{c}44 \pm 5 \\
P<0.001\end{array}$ & $\begin{array}{r}43 \pm 4 \\
P<0.01\end{array}$ & $\begin{array}{r}29 \pm 2 \\
P<0.02\end{array}$ \\
\hline
\end{tabular}

* $T$ pallidum incubated anaerobically and then exposed to $3 \% \mathrm{O}_{2}$ at $34^{\circ} \mathrm{C}$ in vitro.

tMean of counts of 100-300 treponemes in 2 or 3 samples (50-100 treponemes/sample) from duplicate or triplicate culture tubes.

$\mathrm{P}=$ probability; $\mathrm{P}<0.05$ is significant (Student's $t$ test). $\mathrm{NS}=$ not significant.

During aerobic extraction, the minced rabbit testes containing the treponemes were directly exposed to atmospheric oxygen. $T$ pallidum appears to lack the means of detoxifying oxygen-derived species (unpublished data), thus possibly explaining the more rapid decrease in motility and virulence in vitro compared with anaerobically extracted treponemes (table I). The longer survival of the anaerobically extracted treponemes may have been due to: (a) the prevention of the direct reaction of oxygen with key cellular components of $T$ pallidum; (b) a slowing of the rate of production of oxygen-derived free radicals from the medium components; or (c) prevention of a possible oxygen-mediated autolysis of host tissue cells.

Anaerobically harvested treponemes incubated anaerobically for 36 and 48 hours before being exposed to $3 \%$ oxygen survived longer than treponemes incubated under constant 3\% oxygen (tables II and III) but not longer than the control group under constant anaerobic incubation. This may suggest that $T$ pallidum is more sensitive to oxygen during early incubation in vitro.

It is assumed that treponemes which are freshly isolated from the rabbit host are metabolically highly competent. Their endogenous metabolism is presumably very high. A flavoprotein-based energy metabolism, which they are presumed to have, ${ }^{13}$ would result in the production of large amounts of hydrogen peroxide. ${ }^{14}$ This may explain their high sensitivity to oxygen shortly after extraction from tissue even in the presence of reducing agents. What the oxygen requirements are inside the host and how $T$ pallidum avoids the toxicity of oxygen-generated reduction products are as yet unknown. In a recent report of growth of the organism in tissue culture ${ }^{6}$ the oxygen concentration was $1 \cdot 5 \%$. Oxygen may play a very important role in the survival and growth

TABLE III Effect of 36 or 48 hours' anaerobic incubation followed by incubation under $3 \%$ oxygen on the viability of $T$ pallidum as measured by the retention of virulence (latent period of infection)

\begin{tabular}{|c|c|c|c|c|c|c|c|c|}
\hline \multirow[b]{3}{*}{ Incubation conditions } & \multicolumn{8}{|c|}{ Latent periodt (days $\pm S D$ ) of infection after inoculation with treponemes incubated for $(h)$ : } \\
\hline & \multicolumn{3}{|c|}{ Experiment 1} & \multicolumn{3}{|c|}{ Experiment 2} & \multicolumn{2}{|c|}{ Experiment 3} \\
\hline & 72 & 96 & 120 & 72 & 96 & 120 & 60 & 72 \\
\hline Constant $3 \% \mathrm{O}_{2}$ (control) & $7 \cdot 3 \pm 0 \cdot 5$ & $11 \cdot 4 \pm 0 \cdot 5$ & $13 \cdot 5 \pm 0 \cdot 7$ & $10 \cdot 4 \pm 1 \cdot 4$ & $14 \cdot 6 \pm 1 \cdot 0$ & $17 \cdot 0 \pm 0$ & $12 \cdot 6 \pm 1 \cdot 1$ & $11 \cdot 2 \pm 1 \cdot 4$ \\
\hline Anaerobic $(36 h)^{*}$ & $\begin{array}{l}5 \cdot 8 \pm 0.6 \\
P<0 \cdot 001\end{array}$ & $\begin{array}{l}9 \cdot 2 \pm 0.4 \\
\mathrm{P}<0 \cdot 001\end{array}$ & $\begin{array}{l}11 \cdot 4 \pm 0.7 \\
P<0.001\end{array}$ & $\begin{array}{l}8 \cdot 4 \pm 1 \cdot 1 \\
\mathrm{P}<0 \cdot 001\end{array}$ & $\begin{array}{l}12 \cdot 6 \pm 1 \cdot 0 \\
P<0 \cdot 001\end{array}$ & $\begin{array}{l}15 \cdot 2 \pm 0 \cdot 6 \\
P<0 \cdot 001\end{array}$ & $\begin{array}{l}10.7 \pm 0.9 \\
P<0.005\end{array}$ & $\begin{array}{l}9 \cdot 6 \pm 0 \cdot 5 \\
P<0 \cdot 005\end{array}$ \\
\hline Anaerobic $(48 \mathrm{~h})^{*}$ & $\begin{array}{l}6.3 \pm 0.7 \\
P<0.01\end{array}$ & $\begin{array}{l}9.6 \pm 0.5 \\
P<0.001\end{array}$ & $\begin{array}{l}11 \cdot 6 \pm 0.7 \\
P<0 \cdot 001\end{array}$ & $\begin{array}{l}9 \cdot 1 \pm 1.4 \\
P<0.05\end{array}$ & $\begin{array}{l}12 \cdot 6 \pm 0.9 \\
P<0.001\end{array}$ & $\begin{array}{l}15 \cdot 5 \pm 0 \cdot 5 \\
P<0 \cdot 001\end{array}$ & $\begin{array}{l}10 \cdot 5 \pm 1 \cdot 8 \\
P<0 \cdot 01\end{array}$ & $\begin{array}{l}9.8 \pm 0.8 \\
P<0.025\end{array}$ \\
\hline Constant anaerobic (control) & $\begin{array}{l}6 \cdot 8 \pm 1 \cdot 6 \\
\text { NS }\end{array}$ & $\underset{N S}{11 \cdot 1} \pm 0 \cdot 7$ & $\begin{array}{l}13 \cdot 0 \pm 0.7 \\
\mathrm{NS}\end{array}$ & $\begin{array}{l}9 \cdot 2 \pm 1 \cdot 6 \\
\mathrm{NS}\end{array}$ & $\begin{array}{l}12 \cdot 8 \pm 1 \cdot 1 \\
P<0 \cdot 001\end{array}$ & $\begin{array}{l}15 \cdot 8 \pm 0 \cdot 6 \\
P<0 \cdot 001\end{array}$ & $\begin{array}{l}11 \cdot 0 \pm 1 \cdot 5 \\
P<0 \cdot 005\end{array}$ & $\begin{array}{l}9.4 \pm 0.5 \\
P<0.005\end{array}$ \\
\hline
\end{tabular}

* T pallidum incubated anaerobically and then exposed to $3 \% \mathrm{O}_{2}$ at $34^{\circ} \mathrm{C}$ in vitro.

$+T$ ime between inoculation of rabbits and appearance of lesions (mean of 10-12 lesions).

$\mathrm{P}=$ probability; $\mathrm{P}<0.05$ is significant (Student's $t$ test). NS $=$ not significant. 
of $T$ pallidum in vitro, ${ }^{34}$ but the sensitivity of $T$ pallidum to oxygen during extraction from tissue and early incubation in vitro is also very important. Methods used to reduce oxygen toxicity during incubation in vitro may further improve the survival or growth, or both, of $T$ pallidum in vitro.

We gratefully acknowledge the assistance provided by Mrs L Drummond and Dr P Sutrave. We would like to thank Professor S Faine and Dr Ben Adler for constructive critical evaluation.

This work was supported by grants from the Australian National Health and Medical Research Council (NH \& MRC), the Utah Foundation, the Heiser Program, and Monash University.

\section{References}

1. Steiner B, McLean I, Graves S. Redox potential and survival of virulent Treponema pallidum under microaerophilic conditions. Br J Vener Dis 1981:57:295-301.

3. Barbieri J, Cox CD. Pyruvate oxidation by Treponema pallidum. Infect Immun 1979; 25: 157-63.
4. Lysko PG, Cox CD. Respiration and oxidative phosphorylation in Treponema pallidum. Infect Immun 1978;21:462-73.

5. Graves S, Billington T. An optimum concentration of dissolved oxygen for the survival of virulent Treponema pallidum (Nichols strain) under conditions of low oxidation-reduction potential. Br J Vener Dis 1979; 55: 387-93.

6. Fieldsteel AH, Cox DL, Moeckli RA. Cultivation of virulent Treponema pallidum in tissue culture. Infect Immun 1981;32: 908-15.

7. Norris S, Miller J, Sykes J, Fitzgerald TJ. Influence of oxygen tension, sulfhydryl compounds and serum on the motility and $\bar{\omega}$ virulence of Treponema pallidum (Nichols strain) in a cell-free $\vec{T}$ system. Infect Immun 1978; 22:689-97.

8. Fitzgerald TJ, Johnson RC, Wolfe ET. Sulfhydryl oxidation using procedures and experimental conditions commonly used $\omega$ for Treponema pallidum. Br J Vener Dis 1980;56: 129-36.

9. Fitzgerald TJ, Johnson RC, Miller J, Sykes JA. Interaction of . Treponema pallidum (Nichols strain) with cultured mammalian cells: effects of oxygen, reducing agents, serum supplements $\vec{\omega}$ and different cell lines. Infect Immun 1977; 15:444-52.

10. Israeli E. Kohn A, Gitelman J. The molecular nature of $\mathscr{S}$ damage by oxygen to freeze-dried Escherichia coli. Cryobiology 1975; 12: 15-25.

11. Fitzgerald TJ, Johnson RC. Surface mucopolysaccharides of Treponema pallidum. Infect Immun 1979; 24:244-51. 12. Hangaard N. Cellular mechanisms of oxygen toxicity. Physiol $\vec{\omega}$
Rev $1968 ; 48: 311-73$.

13. Lysko P, Cox CD. Terminal electron transport in Treponema pallidum. Infect Immun 1977; 16:885-90.

14. Strittmatter CF. Flavin-linked oxidative enzymes of Lactobacillus casei. J Biol Chem 1959; 234:2784-800. 